\title{
Application of NMR Crystallography to Highly Disordered Templated Materials: Extensive Local Structural Disorder in the Gallophosphate GaPO-34A
}

\author{
Sharon E. Ashbrooka*, Daniel M. Dawsona*, Zhehong Gan ${ }^{b}$, Joseph E. Hoopera, Ivan Hungb, Laurie E. \\ Macfarlanea , David McKaya, Lucy K. McLeodc, and Richard I. Walton ${ }^{c}$ \\ a. School of Chemistry, EaStCHEM and Centre of Magnetic Resonance, University of St Andrews, North Haugh, St \\ Andrews, Fife, KY16 9ST, UK. \\ b. Center of Interdisciplinary Magnetic Resonance, National High Magnetic Field Laboratory, 1800 East Paul Dirac \\ Drive, Tallahassee, FL 32310 \\ c. Department of Chemistry, University of Warwick, Coventry, CV4 7AL, UK.
}

\begin{abstract}
We present an NMR crystallographic investigation of two as-made forms of the recently characterised gallophosphate GaPO-34A, which has an unusual framework composition with a Ga : P ratio of $7: 6$ and contains both hydroxide and fluoride anions and either 1-methylimidazolium or pyridinium as the structure-directing agent. We combine previously reported X-ray crystallographic data with solid-state NMR spectroscopy and periodic density functional theory (DFT) calculations to show that the structure contains at least three distinct types of disorder (occupational, compositional and dynamic). The occupational disorder arises from the presence of six anion sites per unit cell, but a total occupancy of these of five, leading to full occupancy of four sites and partial occupancy of the fifth and sixth (which are related by symmetry). The mixture of $\mathrm{OH}$ and $\mathrm{F}$ present leads to compositional disorder on the occupied anion sites, although the occupancy of some sites by $\mathrm{F}$ is calculated to be energetically unfavorable and signals relating to $\mathrm{F}$ on these sites are not observed by NMR spectroscopy, confirming that the compositional disorder is not random. Finally, a combination of highfield ${ }^{71} \mathrm{Ga}$ NMR spectroscopy and variable-temperature ${ }^{13} \mathrm{C}$ and ${ }^{31} \mathrm{P}$ NMR experiments shows that the structure directing agents are dynamic on the microsecond timescale, which can be supported by averaging the ${ }^{31} \mathrm{P}$ chemical shifts calculated with the SDA in different orientations. This demonstrates the value of an NMR crystallographic approach, particularly in the case of highly disordered crystalline materials, where the growth of large single crystals for conventional structure determination may not be possible owing to the extent of disorder present.
\end{abstract}

\section{Introduction}

Solid-state NMR spectroscopy has long been recognized as a sensitive probe of atomic-scale local structure in materials and of dynamic processes occurring over timescales that vary from nanoseconds to days. ${ }^{1}$ However, in many materials the presence of disorder (spatial, compositional or temporal) leads to complex spectral lineshapes that can be challenging to interpret. ${ }^{2,3}$ In recent years this has led to the development of periodic density functional theory (DFT) codes that can accurately predict NMR parameters from structural models. However, such models are typically based on manual or random modifications of experimentally-derived average structures, and usually need to be optimized before a good match is obtained with experimental NMR parameters. ${ }^{4-6}$ This approach of combining NMR spectroscopy and computational models to provide structural information not readily available from the length-averaged diffraction approaches (or simply in the absence of data from diffraction experiments) has become known as NMR (or SMARTER) crystallography.7-12 In recent years NMR crystallography (with varying levels of input from diffraction-based crystallography) has been applied to great effect on systems including organic solids, ${ }^{13-16}$ porous materials ${ }^{8,17-28}$ and dense phases. ${ }^{29-33}$

Porous materials have been a particular focus of NMR crystallography, as these typically comprise a reasonably well-ordered periodic framework but with pore contents that often exhibit little order on the time and length scales required for diffraction experiments. This is relevant for their practical applications where exchange of, or reactions involving, extra-framework species are the basis of molecular sieving and catalysis. In favorable cases, as demonstrated by Brouwer and co-workers for $\mathrm{SiO}_{2}$ zeolites, ${ }^{18-23}$ NMR crystallography can be used to determine the framework topology and atomic coordinates of microporous materials with minimal (or even no ${ }^{23}$ ) input from diffraction experiments. However, it is more common that some structural information is known from diffraction but, owing to either disorder or small/poor 
quality crystals, it may not be possible to provide a complete picture and NMR crystallography is required to obtain a truly atomic-level description of the structure. This additional information may include the detailed distribution of different cations or anions occupying the same crystallographic sites (compositional disorder), ${ }^{24-26}$ the populations and orientations of species exhibiting spatial disorder, ${ }^{28,34,35}$ and information on the type and timescales of motional processes (temporal disorder). ${ }^{36,37}$

The synthesis of the gallophosphate, GaPO-34A, was first noted by Schott-Darie et $a l^{38}$, who identified it as an impurity phase in the synthesis of GaPO-34 (chabazitetype framework). More recently, we were able to report a reliable synthetic procedure and the crystal structure of two forms GaPO-34A,39 which can be formed from the same precursor gel as GaPO-34, depending on the time for which the gel is aged at room temperature prior to hydrothermal treatment. Prior to the structure being determined by diffraction, multinuclear NMR spectra were also recorded, ${ }^{40}$ which provided important information such as the rather unusual framework stoichiometry (Ga: $\mathrm{P}$ ratio of $7: 6$ ), consistent with elemental analysis, ultimately helping to lead to the structure solution. In our earlier publication, we reported some initial NMR spectra and noted that they indicated the presence of some disorder in the material (as also indicated by the crystallographic measurements carried out). Here, we provide an in-depth multinuclear NMR investigation, combined with DFT calculations, to provide detail beyond that available from the average diffraction structure. GaPO34A provides a particularly complex and interesting example for NMR crystallography, exhibiting compositional and occupational disorder of $\mathrm{OH}$ and $\mathrm{F}$ anions (leading to positional disorder of some framework atoms) and dynamic disorder of the structure directing agent (SDA) molecules.

\section{Experimental Details}

\section{Synthesis}

GaPO-34A was prepared as described previously ${ }^{39}$ with pyridine (py) or 1-methylimidazole (mim) as the SDA, yielding GaPO-34A[pyH] and GaPO-34A[mimH], respectively. A precursor gel of composition $1 \mathrm{Ga}_{2} \mathrm{O}_{3}: 2$ $\mathrm{H}_{3} \mathrm{PO}_{4}: 1 \mathrm{HF}: 70 \mathrm{H}_{2} \mathrm{O}: 1.7 \mathrm{SDA}$ was prepared in the Teflon liner of a $25 \mathrm{~mL}$ autoclave and stirred at room temperature for $1 \mathrm{~h}$. As previously reported, this short aging time is critical for the formation of GaPO-34A, with longer aging times leading to CHA-type GaPO-34..$^{39}$ The autoclave was then sealed and heated to $170{ }^{\circ} \mathrm{C}$ for $24 \mathrm{~h}$. After cooling to room temperature, the white powder was collected by suction filtration, washed with copious amounts of deionized water and dried at $70{ }^{\circ} \mathrm{C}$ in air overnight.

\section{NMR Spectroscopy}

Solid-state NMR spectra were recorded using Bruker Avance III spectrometers equipped with either $9.4 \mathrm{~T}$ or 14.1 $\mathrm{T}$ wide-bore superconducting magnets $\left({ }^{1} \mathrm{H}\right.$ Larmor frequencies of 400.13 and $600.13 \mathrm{MHz}$, respectively) at the University of St Andrews, at the UK $850 \mathrm{MHz}$ solid-state NMR facility using a Bruker Avance II spectrometer equipped with a $20.0 \mathrm{~T}$ wide-bore superconducting magnet $\left({ }^{1} \mathrm{H}\right.$ Larmor frequency of $850.13 \mathrm{MHz}$ ), or at the National High Magnetic Field Laboratory of the US using the $36 \mathrm{~T}$ Series-Connected-Hybrid ( $\mathrm{SCH}$ ) magnet and a Bruker Avance NEO Console. Details of the SCH magnet, field regulation using an external ${ }^{7} \mathrm{Li}$ lock system and operation of the SCH are described elsewhere. ${ }^{41}$ For ${ }^{71} \mathrm{Ga}$ NMR measurement, the SCH magnet was operated at a lower $34.1 \mathrm{~T}$ field due to the limit of tuning frequency of the home-built $3.2 \mathrm{~mm}$ MAS being used. ${ }^{13} \mathrm{C}$ and ${ }^{31} \mathrm{P}$ NMR spectra were recorded with cross polarization (CP) from ${ }^{1} \mathrm{H}$. Key experimental details are given in the figure captions and full details are provided in the Supporting Information (S1). Chemical shifts are reported in ppm relative to $\left(\mathrm{CH}_{3}\right)_{4} \mathrm{Si}\left({ }^{1} \mathrm{H}\right.$ and $\left.{ }^{13} \mathrm{C}\right), \mathrm{CFCl}_{3}\left({ }^{19} \mathrm{~F}\right), 85 \%$ aqueous $\mathrm{H}_{3} \mathrm{PO}_{4}\left({ }^{31} \mathrm{P}\right)$ and $0.1 \mathrm{M}$ aqueous $\mathrm{Ga}\left(\mathrm{NO}_{3}\right)_{3}\left({ }^{71} \mathrm{Ga}\right)$ using Lalanine $\left(\delta\left(\mathrm{NH}_{3}\right)=8.5 \mathrm{ppm}, \delta\left(\mathrm{CH}_{3}\right)=20.5 \mathrm{ppm}\right)$, poly(tetrafluoroethylene) $\left(\delta\left({ }^{19} \mathrm{~F}\right)=-122.7 \mathrm{ppm}\right), \mathrm{BPO}_{4}$ $\left(\delta\left({ }^{31} \mathrm{P}\right)=-29.6 \mathrm{ppm}\right)$ and $\mathrm{GaPO}_{4}$ berlinite $\left({ }^{71} \mathrm{Ga} \delta_{\text {iso }}=111.2\right.$ ppm, $\mathrm{C}_{\mathrm{Q}}=8.8 \mathrm{MHz}, \eta_{\mathrm{Q}}=0.46$ ) as secondary solid references. On the $\mathrm{SCH}$, the ${ }^{71} \mathrm{Ga}$ chemical shift reference was calibrated externally through ${ }^{17} \mathrm{O}$ signal of $\mathrm{D}_{2} \mathrm{O}$ using the method described by Harris et $a l^{42}$ (and references therein).

\section{DFT Calculations}

DFT calculations were carried out using CASTEP 18.1,43 employing the GIPAW approach ${ }^{44}$ to reconstruct the allelectron wavefunction in the presence of a magnetic field. Calculations were performed using the GGA PBE functional, ${ }^{45}$ with dispersion corrections using the scheme of Tkatchenko and Scheffler. ${ }^{46,47}$ Ultrasoft pseudopotentials were used with the inclusion of ZORA scalar relativistic effects, with a modified pseudopotential ${ }^{48}$ for Ga. A planewave energy cutoff of $60 \mathrm{Ry}(\sim 816 \mathrm{eV})$ was used, and integrals over the first Brillouin zone were performed using a Monkhorst-Pack grid ${ }^{49}$ with a $k$-point spacing of 0.03 or $0.042 \pi \AA^{-1}$. Optimization of atomic coordinates and unit cell parameters was carried out prior to calculating NMR parameters. Calculations were performed on a computing cluster at the University of St Andrews, consisting of 90 32-core Intel Broadwell nodes, Infiniband FDR interconnect and a 300 TB GPFS distributed filesystem. Typical calculation times were $\sim 20 \mathrm{~h}$ (geometry optimization) and $\sim 1 \mathrm{~h}$ (NMR parameters), using 192 cores. Isotropic shieldings, $\sigma_{\text {iso, were obtained }}$ from the trace of the absolute shielding tensor, $\sigma$, and isotropic chemical shifts, $\delta_{\text {iso, }}$ were given by $\delta_{\text {iso }}=-\left(\sigma_{\text {iso }}-\right.$ $\left.\sigma_{\mathrm{ref}}\right) / \mathrm{m},{ }^{4}$ where the values used for $\sigma_{\text {ref }}$ and $\mathrm{m}$ were 37.62 ppm and 1.763 for ${ }^{19} \mathrm{~F}$, and $287.1 \mathrm{ppm}$ and 1.165 for ${ }^{31} \mathrm{P}$. The quadrupolar coupling constant, $\mathrm{C}_{\mathrm{Q}}=\mathrm{eQV}_{\mathrm{ZZ}} / \mathrm{h}$, and the asymmetry parameter, $\eta_{\mathrm{Q}}=\left(\mathrm{V}_{\mathrm{XX}}-\mathrm{V}_{\mathrm{YY}}\right) / \mathrm{V}_{\mathrm{ZZ}}$, are obtained directly from the principal components of the electric field gradient tensor, V. Q is the nuclear quadrupole moment, for which values of 146.6 and $107 \mathrm{mb}$ were used for ${ }^{27} \mathrm{Al}$ and ${ }^{71} \mathrm{Ga} .{ }^{50}$

\section{Results and Discussion}

\section{The Average Structure of GaPO-34A}

Figure 1 shows representations of the experimental crystal structures of GaPO-34A[mimH] (from single-crystal 


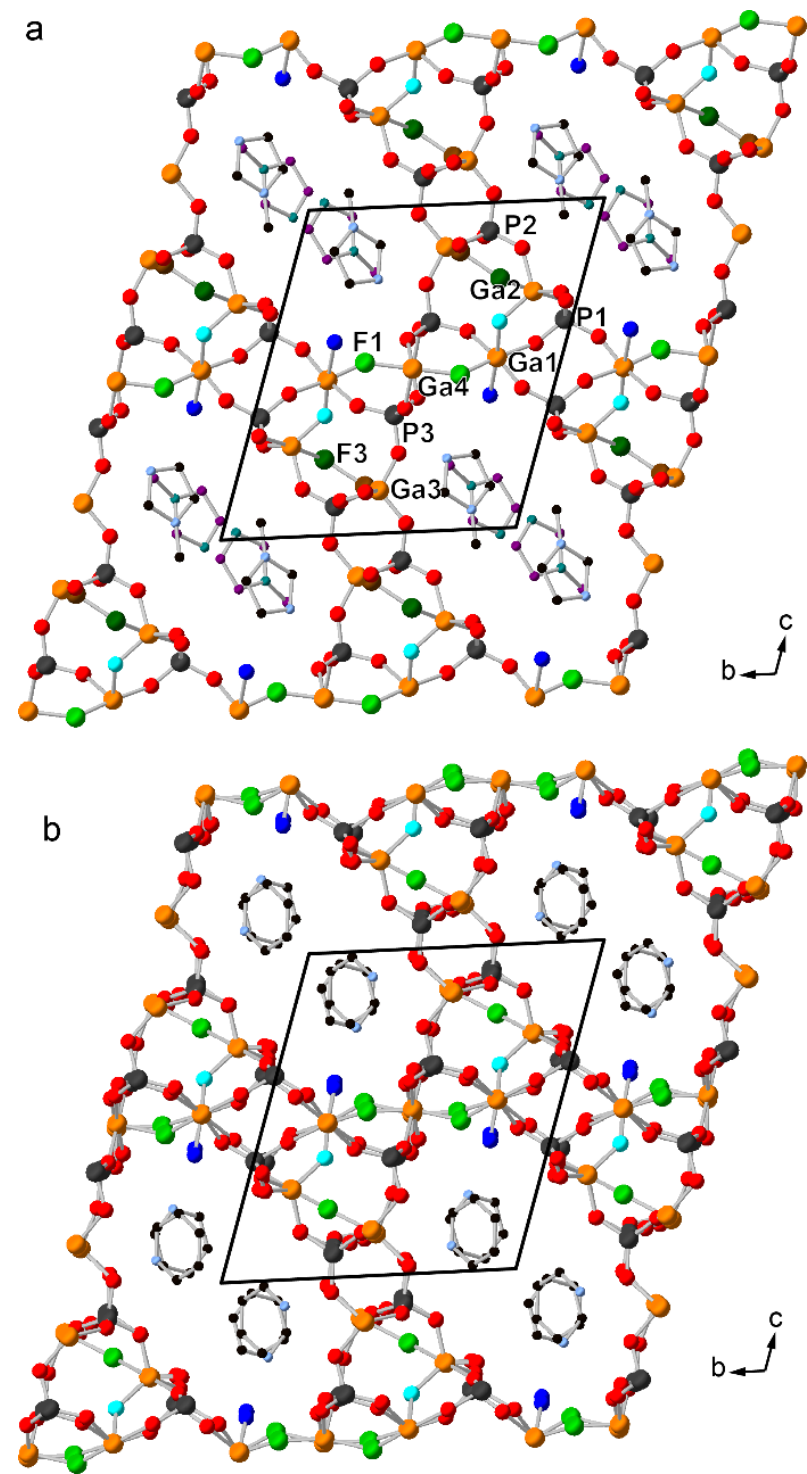

Figure 1. Experimental crystal structures of (a) GaPO$34 \mathrm{~A}[\mathrm{mimH}]$ and (b) GaPO-34A[pyH]. ${ }^{34}$ Atoms are colored with $\mathrm{C}=$ black, $\mathrm{N}=$ pale blue (orientation $\mathrm{A}$ of the SDA, 50\% refined occupancy) $\mathrm{C}=$ purple, $\mathrm{N}=$ teal (orientation $\mathrm{B}$ of the SDA, $33 \%$ refined occupancy), framework $\mathrm{O}=$ red, hydroxyl $\mathrm{O}=$ cyan, water $0=$ dark blue, $\mathrm{F} 1=$ green (100\% refined occupancy), F3 = dark green (33\% refined occupancy), $\mathrm{P}=$ grey, $\mathrm{Ga}=$ orange, $\mathrm{Ga} 3 \mathrm{~A}=$ brown (33\% refined occupancy). $\mathrm{H}$ atoms are not shown or were not located (see ref 39 for further details of the crystal structures). The atom numbering scheme shown assumes that site F3 is vacant: when occupied, the adjacent F1 is termed F2 and the P and Ga sites on the same side of the unit cell are labelled with " $\mathrm{A}$ " and, the position of Ga3A is different from that of $\mathrm{Ga} 3$, as described in more detail in the text.

laboratory X-ray diffraction) and GaPO-34[pyH] (from powder synchrotron diffraction) previously reported by Broom et al. ${ }^{39}$ The framework topology is analogous to that of DIPYR-GaPO, reported by Weigel et al., ${ }^{51}$ although the shapes of the pores in the framework varies significantly depending on the SDA present. The crystal structure determined for GaPO-34A[mimH] contains three distinct $\mathrm{P}$ atoms and four distinct $\mathrm{Ga}$ atoms, with the inversion center at Ga4 giving a $6: 7$ ratio of $\mathrm{P}: \mathrm{Ga}$. In the average crystal structure, there are two types of framework-bound $\mathrm{F}$ anions: F1, which bridges between Ga1 and Ga4, and F3, which bridges between $\mathrm{Ga} 2$ and Ga3. Ga3 was refined as having two possible positions, Ga3 and Ga3A, with $67 \%$ and $33 \%$ occupancy, respectively, and F3 was also refined as having $33 \%$ occupancy, indicating that Ga3A is associated with the presence of F3. F2 is formally related to F1 by inversion but occurs when the closest F3 site is vacant. The partially-occupied F3 site is shown in dark green in Figure 1a. Owing to the excess of $\mathrm{Ga}$ in the framework, all $\mathrm{P}$ atoms have four P-O-Ga linkages, as shown in Figure $2 \mathrm{a}$, but this full condensation is not possible for the $\mathrm{Ga}$ atoms, which have a variety of coordination geometries and numbers, as shown in Figure $2 \mathrm{~b} . \mathrm{Ga} 1$ is octahedral, with three Ga-O-P linkages, one Ga$\mathrm{O}$-Ga linkage, one Ga-F-Ga linkage and one terminal $\mathrm{O}$ atom (where it is assumed, as $\mathrm{H}$ positions are not refined, that the Ga-O-Ga bridge is via $\mathrm{OH}$ and the terminal $\mathrm{O}$ is $\mathrm{H}_{2} \mathrm{O}$ ). $\mathrm{Ga} 2$ is tetrahedral, with three Ga-O-P linkages and a Ga-OGa linkage (again assumed to be $\mathrm{OH}$ ). When F3 is occupied, $\mathrm{Ga} 2$ is pentacoordinate (denoted $\mathrm{Ga} 2 \mathrm{~A}$ ), with an additional Ga-F-Ga linkage to Ga3A (although, unlike Ga3, the position of $\mathrm{Ga} 2$ was not refined as changing with the coordination number). Ga3 is tetrahedral and fully condensed, with four Ga-O-P linkages. When F3 is occupied, Ga3 is vacant and the adjacent pentacoordinate Ga3A site is occupied, with an additional Ga-F-Ga linkage to Ga2A. Ga4 is octahedral and fully condensed, with four Ga-O-P linkages and two GaF-Ga linkages to two different Ga1. The methylimidazolium SDA is refined as disordered over two sites, the first of which (termed orientation A) has 50\% occupancy and the second of which (orientation B) has 33\% occupancy, although it should be noted that there is 1.0 SDA per formula unit, with the remaining 17\% occupying an illdefined orientation that is not considered further in this work or in the published structure (see Supporting Information (S3) for more details). The second $\mathrm{N}$ atom on the imidazolium ring (N3) was not located by diffraction and so, in addition to the two orientations shown in Fig. 1, orientations $\mathrm{A}^{\prime}$ and $\mathrm{B}^{\prime}$ are possible, with the imidazolium rings rotated $180^{\circ}$ about the $\mathrm{H}_{3} \mathrm{C}-\mathrm{N}$ bond. The remaining $17 \%$ of the anion required for charge balancing is assumed to be located on site F3 (to give 50\% total occupancy for each of F3, Ga3 and Ga3A). The published crystal structure has a formula of $\mathrm{Ga}_{7} \mathrm{P}_{6} \mathrm{O}_{24} \cdot(\mathrm{OH})_{2} \cdot\left(\mathrm{H}_{2} \mathrm{O}\right)_{2} \cdot \mathrm{F}_{3} \cdot 2(\mathrm{mimH})$. The structure of GaPO-34A[pyH] was refined with a doubled $a$ axis, compared to GaPO-34A[mimH], allowing the partial occupancy of F3 and the corresponding split-site Ga3 to be explicitly refined as two sites, each with $100 \%$ occupancy. The determined formula of $\mathrm{Ga}_{7} \mathrm{P}_{6} \mathrm{O}_{24} \cdot(\mathrm{OH})_{2} \cdot\left(\mathrm{H}_{2} \mathrm{O}\right)_{2} \cdot \mathrm{F}_{3} \cdot 2(\mathrm{pyH})$, is analogous to that of GaPO-34A[mimH]. However, both descriptions of the disorder are essentially equivalent and, to facilitate comparison of the analogous $\mathrm{Ga}$ and $\mathrm{P}$ species within the two frameworks, we will use the numbering scheme shown in Figures 1 and 2, rather than that originally published.

Figure 3a shows ${ }^{1} \mathrm{H}$ MAS NMR spectra of the two materials, with the resonances at high shift (12.5 and $13.4 \mathrm{ppm}$, for the mim, and pyr forms, respectively) confirming that, as expected, the SDAs are protonated in both cases. As shown 


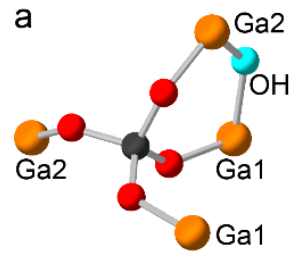

P1

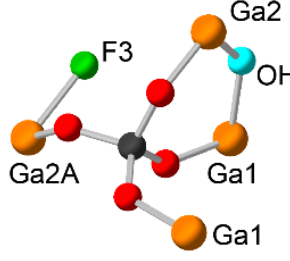

P1A

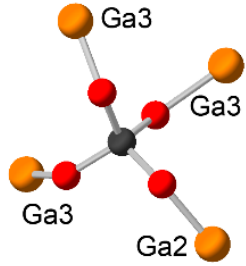

P2

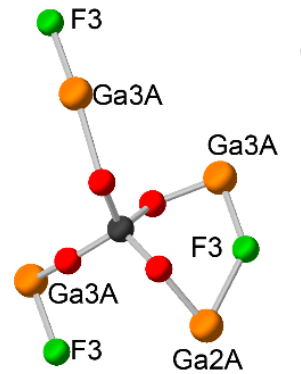

$\mathrm{P} 2 \mathrm{~A}$

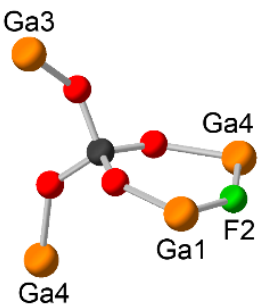

P3

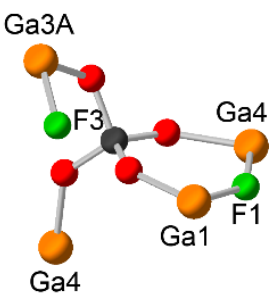

P3A

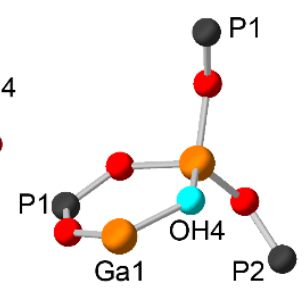

$\mathrm{Ga} 2$

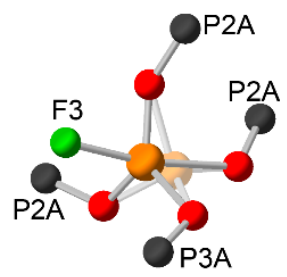

$\mathrm{Ga3A}$

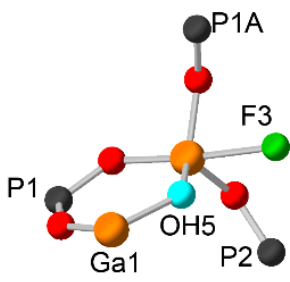

$\mathrm{Ga} 2 \mathrm{~A}$

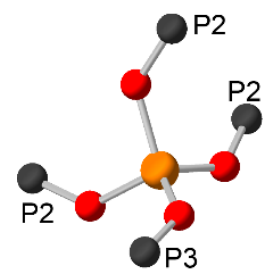

$\mathrm{Ga} 3$

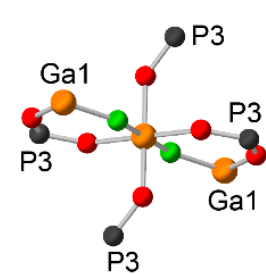

$\mathrm{Ga} 4$

Figure 2. Local environments of the (a) $\mathrm{P}$ and (b) Ga sites in the structure of GaPO-34A[mimH] determined from diffraction. Atoms are colored with framework $\mathrm{O}=$ red, hydroxyl $\mathrm{O}=$ cyan, water $\mathrm{O}=$ dark blue, $\mathrm{F}=$ green, $\mathrm{P}=$ dark grey and $\mathrm{Ga}=$ orange. $\mathrm{H}$ atoms are not shown. Note that, for $\mathrm{P} 1 \mathrm{~A}$, the adjacent $\mathrm{F} 3$ and $\mathrm{OH}$ are in different unit cells, so the presence of F3 does not determine whether P1 is adjacent to $\mathrm{OH} 4$ or OH5. For Ga3A, the position of Ga3 is shown as transparent.

in the Figure S2.1, the ${ }^{1} \mathrm{H}$ NMR spectrum of GaPO-34A[pyH] is highly sensitive to the hydration state of the material and, as such, the following discussion relates only to the spectra of the "as prepared" forms GaPO-34A, which may contain additional molecules of water that have not been located in the crystal structure. The resonances of the SDAs are broadened relative to the those for the same SDAs within the CHA-type framework of GaPO-34,52 confirming that some disorder is present. As previously reported, two-dimensional ${ }^{1} \mathrm{H}$ homonuclear doublequantum (DQ) correlation spectra further revealed the presence of $\mathrm{H}_{2} \mathrm{O}(\delta \approx 3.3 \mathrm{ppm})$ and the resonances between
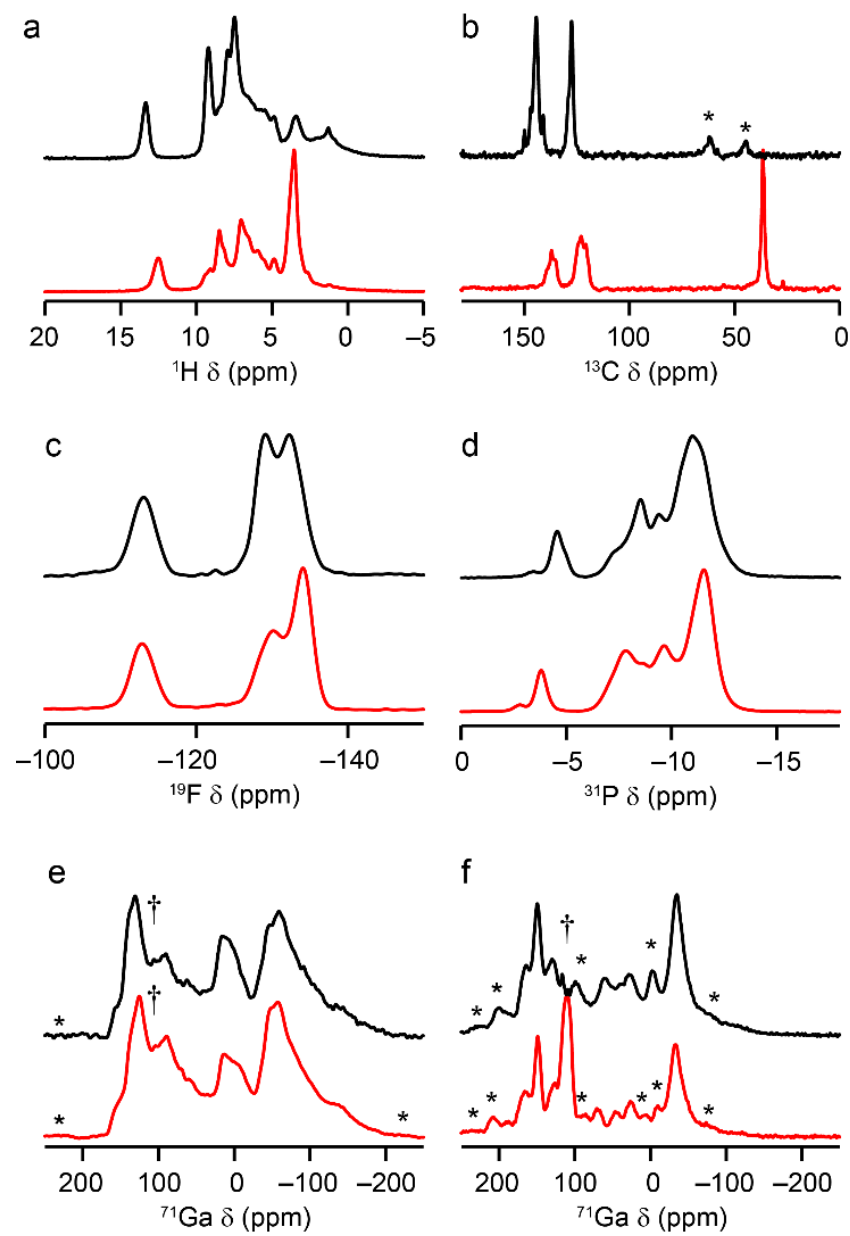

Figure 3. Solid-state NMR spectra of GapO-34A[pyH] (black): (a) ${ }^{1} \mathrm{H}(14.1 \mathrm{~T} 55 \mathrm{kHz} \mathrm{MAS}),(\mathrm{b}){ }^{13} \mathrm{C}$ (CP $14.1 \mathrm{~T} 12.5 \mathrm{kHz}$ MAS), (c) ${ }^{19} \mathrm{~F}$ (14.1 T $55 \mathrm{kHz}$ MAS), (d) ${ }^{31} \mathrm{P}$ (CP $14.1 \mathrm{~T} 14 \mathrm{kHz}$ MAS $293 \mathrm{~K}$ ), (e) ${ }^{71} \mathrm{Ga}\left(20 \mathrm{~T} 50 \mathrm{kHz}\right.$ MAS) and (f) ${ }^{71} \mathrm{Ga}(34.1 \mathrm{~T}, 18$ $\mathrm{kHz}$ MAS) and GaPO-34A[mimH] (red): (a) ${ }^{1} \mathrm{H}(14.1 \mathrm{~T} 60 \mathrm{kHz}$ MAS), (b) ${ }^{13} \mathrm{C}$ (CP $14.1 \mathrm{~T} 12.5 \mathrm{kHz}$ MAS), (c) ${ }^{19} \mathrm{~F}$ (14.1 T $55 \mathrm{kHz}$ MAS), (d) ${ }^{31} \mathrm{P}$ (CP $14.1 \mathrm{~T} 14 \mathrm{kHz}$ MAS, $293 \mathrm{~K}$ ), (e) ${ }^{71} \mathrm{Ga}(20 \mathrm{~T} 60$ $\mathrm{kHz}$ MAS) and (f) ${ }^{71} \mathrm{Ga}(34.6 \mathrm{~T}, 18 \mathrm{kHz}$ MAS). Asterisks (*) indicate spinning sidebands and daggers $(\dagger)$ indicate the position of the ${ }^{71} \mathrm{Ga}$ signal from $\mathrm{GaPO}_{4}$ berlinite $(\sim 5 \%$ impurity in both samples). See Supporting Information (S1) for further experimental details.

4.5 and $6.5 \mathrm{ppm}$ could be assigned to $\mathrm{OH} .{ }^{39}$ The ${ }^{13} \mathrm{C}$ CP MAS NMR spectra of the two materials, shown in Figure $3 \mathrm{~b}$, contain resonances in very similar positions to those for the same SDAs in GaPO-34. ${ }^{52}$ However, the resonances are broadened and split relative to those seen for GaPO-34, again confirming the presence of structural disorder within GaPO-34A. The ${ }^{19} \mathrm{~F}$ MAS NMR spectra of the two materials, shown in Figure 3c appear very similar, with a resonance centered at $-113 \mathrm{ppm}$ and two others between -128 and $-134 \mathrm{ppm}$. These shifts are slightly lower than observed for GaPO-34, but still within the expected range for bridging Ga-F-Ga species (likely indicating a shorter Ga$\mathrm{F}$ bond length in GaPO-34A). ${ }^{52}$ The presence of both $\mathrm{OH}$ and $\mathrm{F}$ suggests that the anion sublattice of GaPO-34A may exhibit compositional disorder (i.e., the anion sites could be occupied by $\mathrm{F}$ or $\mathrm{OH}$ ), which is corroborated by the integrated intensity ratios of the ${ }^{19} \mathrm{~F}$ resonances (approximately $2: 3: 3$ for GaPO-34A[mimH] and $1: 1.2$ : 
1.9 for GaPO-34A[pyH]). The possible presence of disorder on the anion sites is investigated further below.

Both materials contain a small amount of dense $\mathrm{GaPO}_{4}$ berlinite $(\sim 5 \%)$, which gives rise to resonances in the ${ }^{31} \mathrm{P}$ and ${ }^{71} \mathrm{Ga}$ MAS NMR spectra. However, as reported by Broom et al. $^{39}$ and discussed in the Figure S2.2, the ${ }^{31} \mathrm{P}$ NMR spectra can be recorded with $\mathrm{CP}$ from ${ }^{1} \mathrm{H}$, which removes the signal from the aprotic dense phase, yet remains quantitative for the resonances from GaPO-34A. Figure $3 \mathrm{~d}$ shows the ${ }^{31} \mathrm{P}$ CP MAS NMR spectra of the two materials, which contain two resonances at higher shift (2.8 and $-3.8 \mathrm{ppm}$ for GaPO-34A[mimH] and -3.4 and -4.6 ppm for GaPO-34A[pyH]) and a series of signals between 6.6 and $-12.4 \mathrm{ppm}$ in both cases. It is challenging even to decompose the overlapped spectral lineshapes into a reliable number of resonances, let alone obtain accurate integrals. However, it is clear from Figure $3 \mathrm{~d}$ that more than six well-defined resonances are present in both spectra, as might be expected given the disordered nature of the structure. The effects of $\mathrm{OH} / \mathrm{F}$ disorder on the anion sites in aluminophosphates (AlPOs) has been investigated by Martineau et al. for AlPO-CJ2 and AlPO-CLO,24,25 with a Ga-bound $\mathrm{OH}$ anion leading to a $c a .1 .5 \mathrm{ppm}$ higher shift for connected $\mathrm{P}$ than $\mathrm{F}$ in the same site. Therefore, the splitting of the ${ }^{31} \mathrm{P}$ resonances could be attributed at least partially to disorder on the anion site, as proposed above. While it has been demonstrated in aluminophosphates that lowpower ${ }^{27} \mathrm{Al}$ decoupling can provide impressive resolution enhancement for ${ }^{31} \mathrm{P}$ NMR spectra, ${ }^{53,54}$ such an approach is not as straightforward for GaPOs owing to the two NMRactive isotopes of $\mathrm{Ga},{ }^{69} \mathrm{Ga}(\mathrm{I}=3 / 2,60.1 \%$ natural abundance) and ${ }^{71} \mathrm{Ga}(\mathrm{I}=3 / 2,39.9 \%$ natural abundance), both of which would need to be decoupled. In addition, both isotopes of $\mathrm{Ga}$ tend to have larger $\mathrm{C}_{\mathrm{Q}}$ than ${ }^{27} \mathrm{Al}$, such that decoupling conditions would likely be more challenging. ${ }^{55}$ Such an approach would also be unlikely to yield significant resolution enhancement for a material as disordered as GaPO-34A, in which the linewidths are dominated by a chemical shift distribution.

The quadrupolar characteristic of ${ }^{71} \mathrm{Ga}(\mathrm{I}=3 / 2)$ means that, despite a shift range here of $\sim 200 \mathrm{ppm}$, the individual resonances are significantly broadened and overlapped even at an external field strength of $20.0 \mathrm{~T}$ (Figure 3e). Signals can be observed for tetrahedral, pentacoordinate and octahedral Ga (denoted $\mathrm{Ga}^{\mathrm{IV}}, \mathrm{Ga}^{\mathrm{V}}$ and $\mathrm{Ga}^{\mathrm{VI}}$, respectively, spanning the shift ranges of 170 to 45,45 to -25 and -25 to $-200 \mathrm{ppm}$ ) with an approximate integrated intensity ratio of $2.5: 1: 2.5$ and $1.8: 1: 2$ (for GaPO-34A[mimH] and $\mathrm{GaPO}-34 \mathrm{~A}[\mathrm{pyH}]$, respectively), in poor agreement with the anticipated intensities of $2: 2: 3$ based on the published crystal structures. In an attempt to obtain higher resolution ${ }^{71} \mathrm{Ga}$ NMR spectra were recorded at $34.1 \mathrm{~T}$ (but with slower MAS) and are shown in Figure 3f. Slightly different intensity ratios of $1.9: 1: 1.8$ and $2.0: 1: 2.2$, respectively, were obtained, suggesting that, even at these very high fields, spectral intensities have contributions from overlapping resonances and spinning sidebands. However, it should be noted that the broad resonances observed for ${ }^{71} \mathrm{Ga}$, even at $34.1 \mathrm{~T}$, necessitate the use of a spin echo pulse sequence to minimize baseline distortions and the spectra are, consequently, not expected to be truly quantitative.

\section{Anion Disorder in GaPO-34A}

From the crystal structure and proposed formula of GaPO$34 \mathrm{~A}$, one would expect a ratio of F1 : F2 : F3 of $1: 1: 1$, which is in poor agreement with the intensities of the signals observed in the ${ }^{19} \mathrm{~F}$ NMR spectra. In addition to these different and unexpected intensity ratios, the signals at $-113 \mathrm{ppm}$ in both materials have much slower spinlattice relaxation than the other two signals, with time constants $\left(\mathrm{T}_{1}\right)$ summarized in Table 1 . A ${ }^{19} \mathrm{~F}$ doublequantum (DQ) NMR spectrum of GaPO-34A[mimH], shown in Figure 4a, reveals that the slowest-relaxing ${ }^{19} \mathrm{~F}$ nuclei are spatially separate from the others. This combination of very different relaxation behavior and spatial separation may seem indicative of the presence of two separate phases in the sample. However, as reported previously, ${ }^{39}$ the powder XRD patterns refined well with a single phase with only a minor impurity of $\mathrm{GaPO}_{4}$ berlinite. Furthermore, as shown in Figures $4 \mathrm{~b}$ and $4 \mathrm{c}$, all three ${ }^{19} \mathrm{~F}$ signals could be correlated with ${ }^{31} \mathrm{P}$ signals from the GaPO$34 \mathrm{~A}$ framework, and also with ${ }^{1} \mathrm{H}$ signals from the methylimidazolium SDA. It can, therefore, be concluded that all observed ${ }^{19} \mathrm{~F}$ resonances arise from the same phase, but that there must be very different local $\mathrm{F}$ environments present.

The use of DFT calculations to assist in the interpretation and assignment of NMR spectra of disordered materials is now relatively well established. ${ }^{2-4}$ Here, ordered model structures of GaPO-34A[mimH] were generated based on a single unit cell of the experimental structure determined from diffraction, with all possible combinations and permutations of $\mathrm{OH}$ and $\mathrm{F}$ occupying the five different anion sites, while the SDA was fixed in the orientation that was refined to have the highest occupancy (other models with the SDA occupying orientations A', B and B' showed little difference in favored fluorination sites, as discussed further in the Supporting Information, Figures S3.3-S3.6). These structures were optimized and their relative energies and NMR parameters calculated as described above (see Figures S3.7-S3.9 for NMR parameters of alternative cation orientations). Figure 5 shows plots of the

Table 1. Summary of the isotropic shifts, relative spectral intensities and $T_{1}$ relaxation constants of the ${ }^{19} \mathrm{~F}$ resonances observed for GaPO-34A. See Supporting Information (S1) for further experimental details.

\begin{tabular}{cccc}
\hline Material & ${ }^{19} \mathrm{~F} \delta_{\text {iso }}(\mathrm{ppm})$ & Intensity (\%) & $\mathrm{T}_{1} / \mathrm{s}$ \\
\hline GaP0-34A[mimH] & $-113.0(1)$ & 24.7 & $39(2)$ \\
& $-130.2(1)$ & 37.7 & $6(1)$ \\
& $-134.2(1)$ & 37.5 & $6(1)$ \\
GaPO-34A[pyH] & $-113.0(1)$ & 24.6 & $43(2)$ \\
& $-128.9(1)$ & 28.6 & $16(1)$ \\
& $-132.4(1)$ & 46.7 & $16(1)$ \\
\hline
\end{tabular}



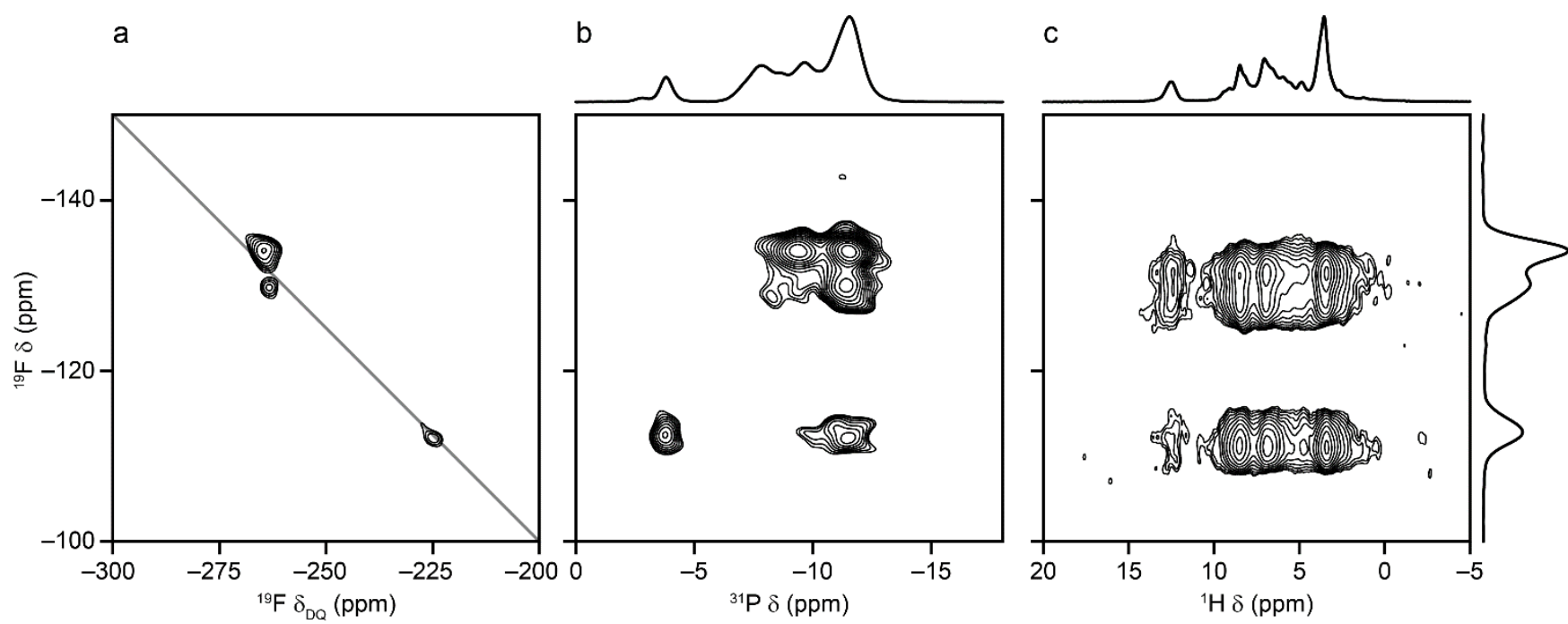

Figure 4. (a) ${ }^{19} \mathrm{~F}$ (14.1 T, $55 \mathrm{kHz}$ DQMAS), (b) ${ }^{19} \mathrm{~F}-31 \mathrm{P}$ (14. $1 \mathrm{~T}, 50 \mathrm{kHz}$ MAS) CP-HETCOR and (c) ${ }^{19} \mathrm{~F}-{ }^{1} \mathrm{H}$ (9.4 T, $40 \mathrm{kHz}$ MAS) HMQC spectra of GaPO-34[mimH]. Note that, for presentation purposes, the spectrum in (a) has been rotated such that $\delta_{2}$ (the ${ }^{19} \mathrm{~F}$ MAS dimension) is along the vertical axis. The grey line in (a) shows the $\delta_{1}=2 \delta_{2}$ double-quantum autocorrelation diagonal. The ${ }^{1} \mathrm{H}$, ${ }^{19} \mathrm{~F}$ and ${ }^{31} \mathrm{P}$ NMR spectra from Figure 3 are shown along the relevant axes. See Supporting Information (S1) for further experimental details.

energy relative to the lowest-energy structure of that composition $\left(E_{r e l}\right)$ and the mixing energy ( $E_{\text {mix }}$, given by the difference in energy between the mixed-anion material and stoichiometric amounts of the single-anion materials) for the structural models containing different numbers and arrangements of $\mathrm{F}$ anions, where the $\mathrm{x}$ positions of each set
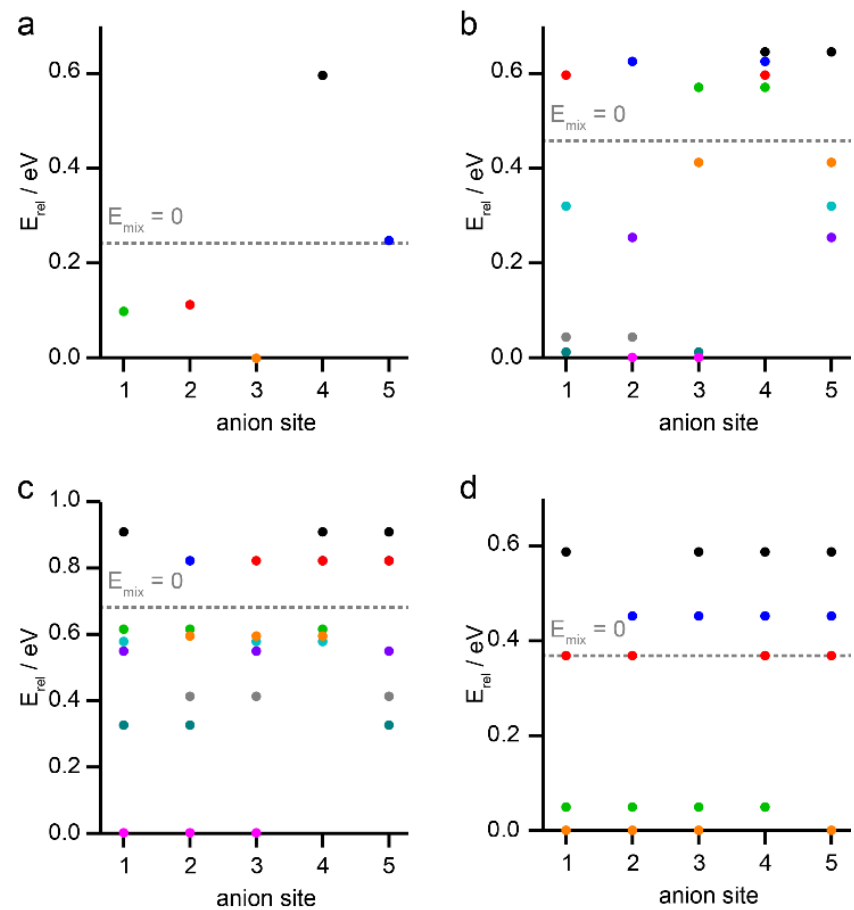

Figure 5. Plots of relative energies ( $\mathrm{E}_{\text {rel }}$ ) of models of GaPO$34 \mathrm{~A}[\mathrm{mimH}]$ with different numbers of anion sites occupied by $\mathrm{F}$ and all remaining anion sites occupied by $\mathrm{OH}$. Models have (a) one, (b) two, (c) three and (d) four F anions per unit cell. Dashed lines indicate $\mathrm{E}_{\text {mix }}=0$ for each specified composition. See Supporting Information (S3) for further details and additional models with different SDA orientations. of colored points indicate the anion sites occupied by $\mathrm{F}$ in that model. It is clear that, when one F is incorporated into the structure, fluorination of sites 1,2 and 3 is favored relative to fluorination of sites 4 and 5 (Figure 5a), and the mixing energies obtained for fluorination of sites 4 or 5 are unfavorable. When two $F$ are present (Figure 5b), structures with sites 4 and 5 both occupied by $\mathrm{OH}$ are much more favorable, but the mixing energies suggest that fluorination of site 5 may be observed when one of sites 1 , 2 or 3 are also fluorinated, while models with site 4 fluorinated are still disfavored The close proximity of sites 3 and 5 (around $2.6 \AA$ ) explains the preference for fluorination of site 5 over site 4 , since an $\mathrm{OH}$ group on either site 3 or site 5 can form a favorable $\mathrm{O}-\mathrm{H} \cdots \mathrm{O}_{\text {(framework) }}$ hydrogen bonding interaction with the same framework 0 atom, as shown in Figure $6 \mathrm{a}$ and $\mathrm{b}$. However, when $\mathrm{OH}$ is present on both sites 3 and 5, there is competition for the hydrogen bond acceptor and both interactions are weakened (the $0-\mathrm{H} \cdots \mathrm{O}$ angles become more acute and the $\mathrm{H} \cdots \mathrm{O}$ distance increases, as shown in Figure $6 \mathrm{c}$ ). This can be confirmed by noting that fluorination of both sites 3 and 5 is less favorable than an $\mathrm{OH} / \mathrm{F}$ pair on these two sites, since either $\mathrm{OH} / \mathrm{OH}$ or $\mathrm{F} / \mathrm{F}$ reduces the possibility of forming one strong hydrogen bond. Fluorination of site 4 is, likewise, disfavored owing to the loss of the strong hydrogen bond shown in Figure 6d. Figure 5c shows that, when three $F$ are present, even models with site 4 fluorinated can have a favorable $E_{\text {mix }}$, although two of sites 1, 2 and 3 must be fluorinated to achieve this. In agreement with the results for models containing one fluorine atom, simultaneous fluorination of sites 1,2 and 3 is $0.32 \mathrm{eV}$ more favorable than the next most favorable model (fluorination of sites 1, 2 and 5, which still contains an $\mathrm{OH} / \mathrm{F}$ pair on sites 3 and 5) and, in general, fluorination of site 4 is still less favorable than fluorination of site 5 . When four $F$ are present in the cell (Figure $5 \mathrm{~d}$ ), models where sites 1, 2 and 3 are fluorinated along with either site 4 or 5 are favored over models with both sites 4 and 5 
a
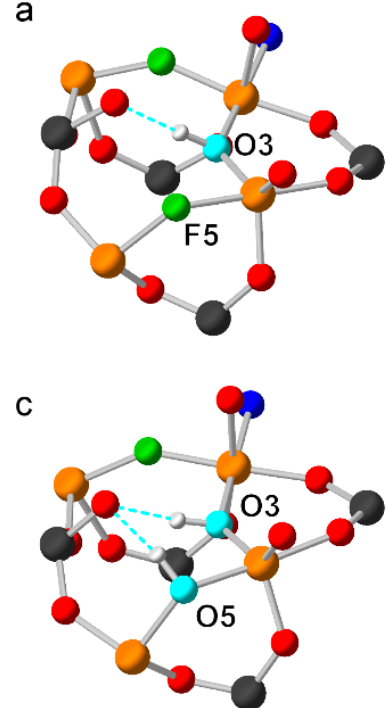

Figure 6. Hydrogen bonding arrangements for $\mathrm{OH}$ located on anion sites 3 and 5 in optimized models of GaPO-34A[mimH], where all other anion sites are occupied by $\mathrm{F}$ and the SDA is in orientation A. (a) $\mathrm{OH}$ on site $3, \mathrm{~F}$ on site 5 - the $\mathrm{OH} \cdots \mathrm{O}$ distance is $1.65 \AA$ and the $\mathrm{O}-\mathrm{H} \cdots \mathrm{O}$ angle is $166.6^{\circ}$, (b) F on site 3 , $\mathrm{OH}$ on site $5-$ the $\mathrm{OH} \cdots \mathrm{O}$ distance is $1.94 \AA$ and the $\mathrm{O}-\mathrm{H} \cdots \mathrm{O}$ angle is $172.0^{\circ}$, (c) $\mathrm{OH}$ on sites 3 and 5 - for site 3 the $\mathrm{OH} \cdots \mathrm{O}$ distance is $1.74 \AA$ and the $0-\mathrm{H} \cdots 0$ angle is $158.5^{\circ}$ and for site 5 the $\mathrm{OH} \cdots \mathrm{O}$ distance is $2.08 \AA$ and the $\mathrm{O}-\mathrm{H} \cdots \mathrm{O}$ angle is $158.6^{\circ}$. (d) Hydrogen bonding arrangement for $\mathrm{OH}$ in anion site 4 with all other anion sites occupied by $\mathrm{F}$ and the SDA in the A orientation - the $\mathrm{OH} \cdots \mathrm{O}$ distance is $1.90 \AA$ and the $\mathrm{O}-\mathrm{H} \cdots \mathrm{O}$ angle is $175.1^{\circ}$. Atoms are colored with $\mathrm{H}=$ light grey, framework $\mathrm{O}=$ red, hydroxyl $\mathrm{O}=$ cyan, water $\mathrm{O}=$ dark blue, $\mathrm{F}$ $=$ green, $\mathrm{P}=$ dark grey and $\mathrm{Ga}=$ orange.

fluorinated. It therefore seems likely on the grounds of energetics that fluorine will mainly occupy sites 1, 2 and 3 regardless of the total fluorine content of the material, but some fluorination of site 5 , and possibly even of site 4 cannot be ruled out entirely at a composition of $3 \mathrm{~F}$ per unit cell (i.e., close to the average experimental compositions of the materials studied here).

Figure 7 shows the experimental ${ }^{19} \mathrm{~F}$ MAS and ${ }^{31} \mathrm{P}$ CP MAS NMR spectra of GaPO-34A[mimH], overlaid with the calculated values of $\delta_{\text {iso }}$ for each of the $F$ and $P$ sites in the structural models considered above. The tentative conclusions about the occupancies of the anion sites based on energetics is supported by the calculated ${ }^{19} \mathrm{~F}$ peak positions (Figure 7a), which suggest that the resonance at higher shift and with longer $\mathrm{T}_{1}$ relaxation can be assigned to F3, whereas the two resonances at lower shift and with similar $\mathrm{T}_{1}$ values can be assigned to the very similar species, F1 and F2. In light of this assignment, the difference in $\mathrm{T}_{1}$ relaxation constants may explain the appearance of the ${ }^{19} \mathrm{~F}$ DQMAS spectrum in Figure 4a: the shortest F-F contacts are $3.9 \AA$ for F1-F2, $4.8 \AA$ for F1-F3 and $5.1 \AA$ for F3-F3, but the much longer coherence lifetimes for F3 mean that DQ coherences may build up through weaker dipolar couplings. There is no indication of any spectral intensity that could be assigned to F4 and, while it is possible that signals from $\mathrm{F} 5$ could contribute to the signal at -130 to $-134 \mathrm{ppm}$, this resonance would be a

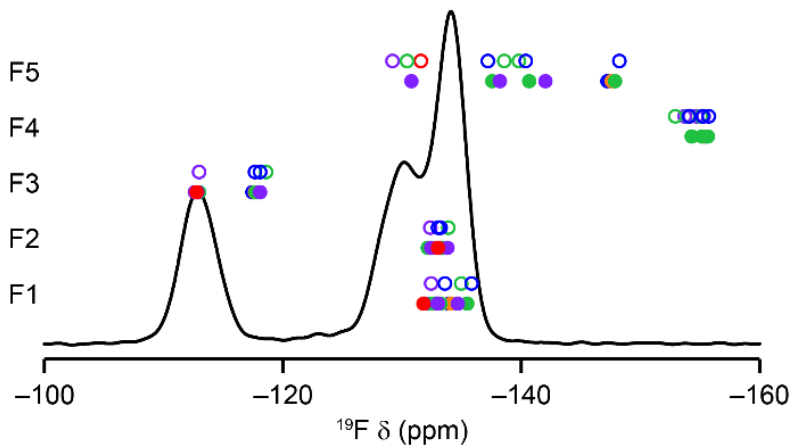

b

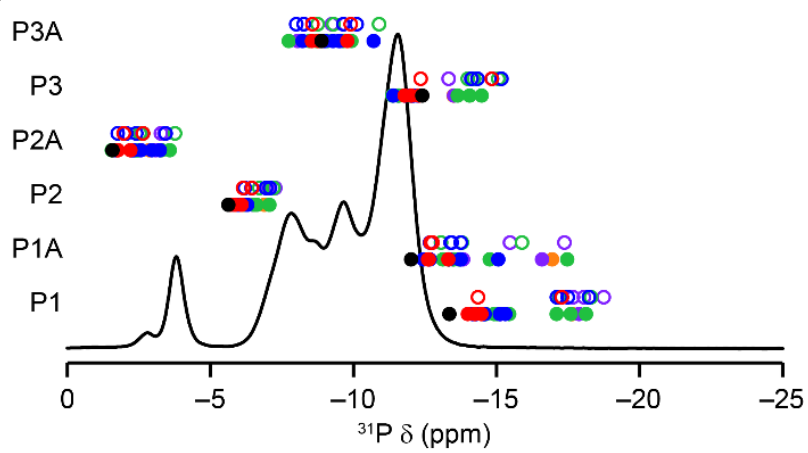

Figure 7. (a) ${ }^{19} \mathrm{~F}$ and (b) ${ }^{31} \mathrm{P} \delta_{\text {iso }}$ calculated for the different sites in models of GaPO-34A[mimH] with $0-5 \mathrm{~F}$ anions per unit cell (and all other anion sites occupied by $\mathrm{OH}$ ). Calculated points are overlaid onto the experimental spectra presented in Figure 3. Open points indicate structures with an unfavorable $E_{\text {mix }}$ and filled points indicate a favorable Emix (note that, for the end members with 0 and $5 \mathrm{~F}$ per cell, there is only one model with $E_{\text {mix }}=0$ ). See Supporting Information (S3) for further details and models with different SDA orientations.

expected to be broadened to lower shifts, which is not observed. (It should be noted that structures with fluorination on F3 lead to shifts for F5 of around -140 to $148 \mathrm{ppm}$, whereas models with $\mathrm{OH}$ on site 3 and $\mathrm{F}$ on site 5 give F5 shifts of around -129 to $-139 \mathrm{ppm}$, so a tail to lower shifts would indicate the presence of less favorable $\mathrm{F} / \mathrm{F}$ pairs on sites 3 and 5.) Assignment of the ${ }^{31} \mathrm{P}$ resonances is more challenging since, as shown in Figure $7 \mathrm{~b}$, not only is there more overlap of spectral resonances, but the calculated shift ranges for the different $\mathrm{P}$ species are overlapped in all cases other than the resonances at 2.8 and $-3.8 \mathrm{ppm}$, which can be assigned to P2A. From the ${ }^{19} \mathrm{~F}-31 \mathrm{P}$ correlation shown in Figure $4 \mathrm{~b}$, the resonance at $3.8 \mathrm{ppm}$ can be assigned to P2A associated with $\mathrm{F}$ on site 3, whereas the less intense resonance at $-2.8 \mathrm{ppm}$ can be assigned to P2A associated with a hydroxide on site 3 (which, given the composition of the material, may be expected to be disfavored, $c f$. Figure $5 c$ ). The order of magnitude of this shift difference and the slightly lower ${ }^{31} \mathrm{P}$ shift of the fluorinated species is consistent with previous observations of ${ }^{31} \mathrm{P}$ NMR spectra of mixed OH/F AlPOs. ${ }^{24,25}$

While full assignment is not possible using the DFT calculations alone, these provide a starting point for further assignment of the ${ }^{19} \mathrm{~F}$ and ${ }^{31} \mathrm{P}$ resonances, which 
can be made by consideration of the crystal structure and the ${ }^{19} \mathrm{~F}-{ }^{31} \mathrm{P}$ correlation spectrum shown in Figure $4 \mathrm{~b}$. The correlation at $\left(\delta\left({ }^{31} \mathrm{P}\right), \delta\left({ }^{19} \mathrm{~F}\right)\right)=(-11.4,-113) \mathrm{ppm}$ arises from a P species close to F3, which could be P1A or P3A, both of which are relatively close (within $4 \AA$ ) to anion site 3. Indeed, as this is the only other correlation between F3 and $\mathrm{a}^{31} \mathrm{P}$ resonance, it can be concluded that $\mathrm{P} 1 \mathrm{~A}$ and $\mathrm{P} 3 \mathrm{~A}$ are coincident in chemical shift. P3A is only near to F3, whereas P1A is also close to $\mathrm{F} 1$ and $\mathrm{F} 2$, giving rise to the correlations at $(-11.4,-130)$ and $(-11.4,-134)$ ppm. P2 and P3 are only close to anion site 4, which is energetically unlikely to be occupied by $\mathrm{F}$ and, therefore, signals from these species would not be expected to be observed in Figure $4 \mathrm{~b}$. From the calculated shift ranges for these species presented in Figure $7 \mathrm{~b}$, the ${ }^{31} \mathrm{P}$ resonance at -7.2 ppm can be assigned to P2 and that at -10.4 ppm to P3. The remaining intense ${ }^{31} \mathrm{P}-19 \mathrm{~F}$ correlation at $(-9.4,-134)$ ppm can, therefore, be assigned to a correlation between P1 and F2, with a low-intensity resonance at $(-9.4,-130)$ ppm attributed to a correlation between P1 and F1, which occurs over a slightly longer range ( $4.0 \AA$ compared to 3.3 $\AA$ for P1-F2). This final point means that the assignment of the ${ }^{19} \mathrm{~F}$ resonances at -130 and -134 ppm must be $\mathrm{F} 1$ and F2, respectively, although the DFT calculations (Figure 7b) indicate that the ranges for these species may overlap. One final point of note is that the presence of the ${ }^{19} \mathrm{~F} D Q$ correlation corresponding to F3-F3 indicates that there must be some longer-range ordering along the crystallographic $a$ axis such that pairs of F3 are occupied on the same side of adjacent unit cells.

Multinuclear or multidimensional NMR experiments involving ${ }^{71} \mathrm{Ga}$ are challenging owing to the quadrupolar interaction, which necessitates rapid MAS (i.e., small sample volume) and high magnetic fields. Even at $20.0 \mathrm{~T}$, it was not possible to obtain sufficient sensitivity for ${ }^{19} \mathrm{~F}-{ }^{71} \mathrm{Ga}$ or ${ }^{31} \mathrm{P}-{ }^{71} \mathrm{Ga}$ experiments to gain any further structural insight into GaP0-34A. However, there remains the question of the precise number of ${ }^{71} \mathrm{Ga}$ resonances in the spectra shown in Figure 3. A multiple-quantum (MQ) MAS experiment would be an option to obtain a higherresolution isotropic ${ }^{71} \mathrm{Ga}$ NMR spectrum, but this experiment is particularly insensitive in the regime of fast MAS and large quadrupolar coupling, ${ }^{56}$ such that no useful signal was obtained at $20.0 \mathrm{~T}$, even with attempts using FAM-N ${ }^{57}$ (which does not require knowledge of the values of $C_{Q}$ ) to enhance the efficiency of the conversion of MQ coherences. An alternative to MQMAS is to use the satellite transition (ST) MAS experiment, which has much higher sensitivity and is more tolerant of larger values of $\mathrm{C}_{Q} .{ }^{56}$ While the experiment does have the rather exacting technical demands of a very well-set magic angle (to within $0.001^{\circ}$ ), very stable MAS (ideally within $\pm 2 \mathrm{~Hz}$ ) and accurate rotor synchronization of pulses, these are achievable using modern hardware. Figure 8 shows the ${ }^{71} \mathrm{Ga}$ STMAS NMR spectrum of GaPO-34A[mimH], which contains only one signal, corresponding to the $5 \%$ berlinite impurity. The observation of this signal is both evidence that the angle is well set and the MAS rate is stable, and testament to the exceptionally high sensitivity of the STMAS experiment. However, the question remains as to why the $95 \%$ of the signal corresponding to GaPO$34 \mathrm{~A}[\mathrm{mimH}]$ is not observed. Antonijevic et al. ${ }^{36}$ observed a

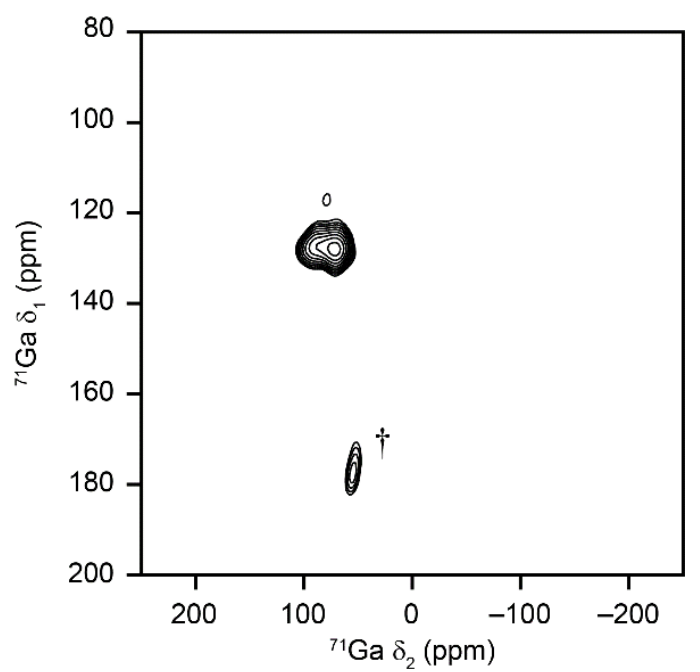

Figure 8. ${ }^{71} \mathrm{Ga}(20.0 \mathrm{~T}, 60 \mathrm{kHz}$ MAS) STMAS NMR spectrum of GaPO-34A[mimH]. The resonance corresponding to the central-transition autocorrelation signal is indicated with a dagger ( $\dagger$ ). See Supporting Information (S1) for further experimental details.

similar phenomenon in the ${ }^{27} \mathrm{Al}$ STMAS NMR spectra of AlP0-14, which was shown to arise from microsecond dynamics broadening the ST spinning sidebands. This phenomenon leads to signals that can be broadened beyond the limit of detection in the STMAS spectrum. ${ }^{58}$ Therefore, the lack of any signal from GaPO-34A[mimH] in Figure 8 provides strong evidence that, in addition to the static disorder discussed above, there is likely to be at least one dynamic process occurring within the material.

\section{SDA Dynamics in GaPO-34A}

In a GaPO, the SDA or any water molecules within the pores may be dynamic, as might the flexible framework itself. Figure 9 shows variable-temperature (VT) ${ }^{13} \mathrm{C},{ }^{19} \mathrm{~F}$ and ${ }^{31} \mathrm{P}$ NMR spectra of GaP0-34A[mimH], from which it is clear that the spectrum, and therefore the structure, varies with temperature. While the static disorder discussed above precludes a detailed analysis of these VT NMR spectra, some key observations can provide insight into the nature of the motion present. Firstly, the $\mathrm{CH}_{3}$ signal narrows with increasing temperature and the splitting observed at $273 \mathrm{~K}$ is absent at $343 \mathrm{~K}$ (Figure 9a). However, while the aromatic $\mathrm{CH}$ signals change in shape and do narrow slightly, they do not resolve neatly to the three resonances observed for GaPO-34[mimHF]..$^{52}$ Secondly, the P1 and P2 signals are much more sensitive to changes in temperature than the P1A, P2A, P3A and P3 signals (Figure $9 b)$. Finally, the ${ }^{19} \mathrm{~F}$ resonances are all affected differently by changes in temperature (Figure 9c), although all resonances exhibit a slight move to higher shift with increasing temperature, consistent with lengthening of the Ga-F bonds. ${ }^{52}$ These observations, taken together, suggest that, on the microsecond timescale, the SDAs may switch between the different crystallographic orientations identified in the diffraction structure, with this reorientation becoming more rapid with increasing temperature. The framework itself is not dynamic on the longer range (e.g., in the sense of "breathing"), as evidenced by the VT X-ray diffraction experiments of 

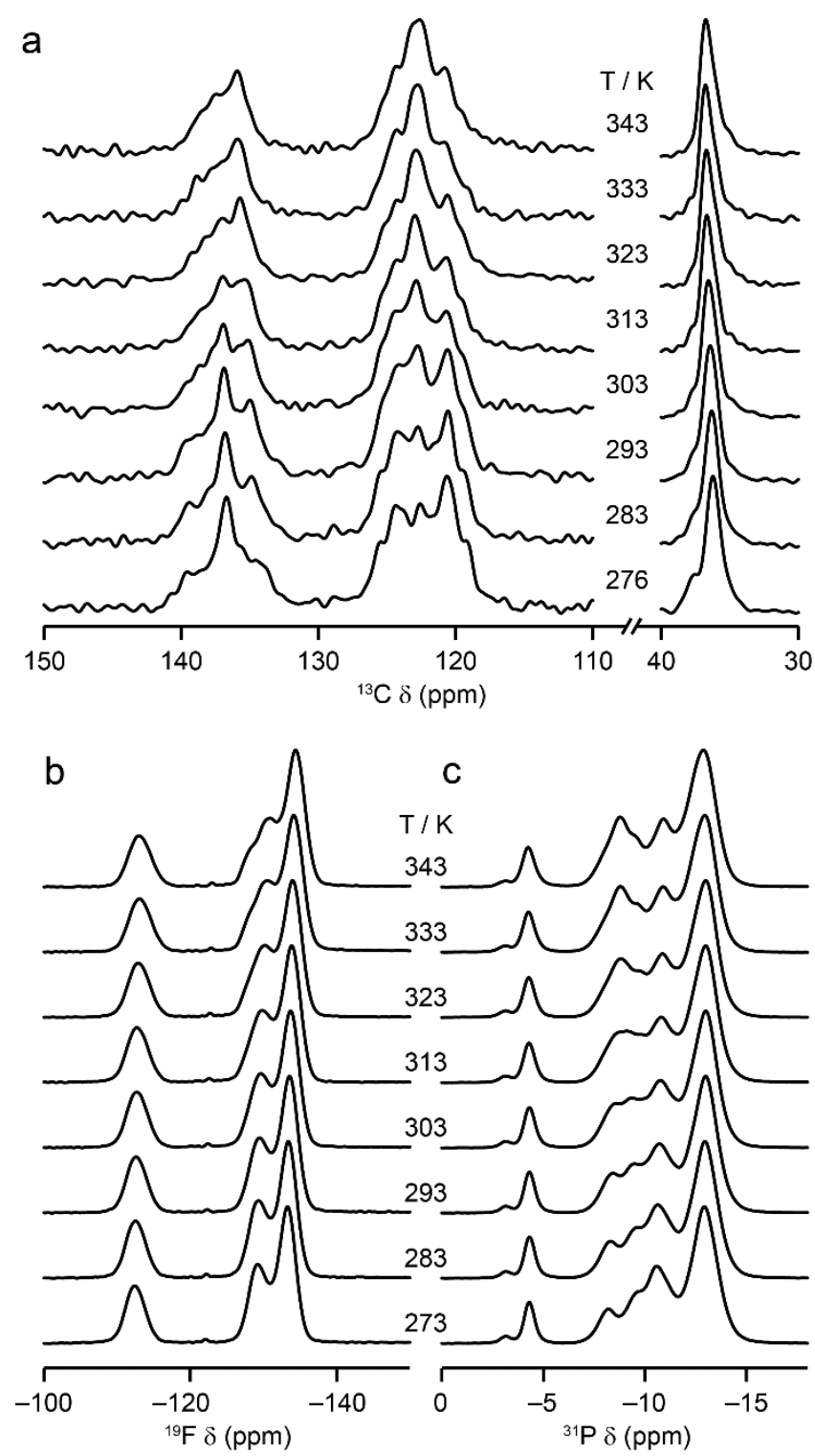

Figure 9. (a) ${ }^{13} \mathrm{C}\left(9.4 \mathrm{~T}, 12.5 \mathrm{kHz}\right.$ CP MAS), (b) ${ }^{19} \mathrm{~F}(14.1 \mathrm{~T}, 35$ $\mathrm{kHz}$ MAS) and (c) ${ }^{31} \mathrm{P}(14.1 \mathrm{~T}, 12.5 \mathrm{kHz}$ CP MAS) variabletemperature NMR spectra of GaPO-34[mimH]. See Supporting Information (S1) for further experimental details.

Broom et al.,39 which show no significant changes in the position of the Bragg peaks from the framework until the onset of decomposition. However, the parts of the framework closest to the SDA, and those with the greatest flexibility (i.e., P1 and P2, which are not part of threemembered rings) do experience a temperature-dependent environment owing to the reorientation of the nearby molecules. This is supported by the calculated ${ }^{31} \mathrm{P} \delta_{\text {iso, }}$, which shows significant variation with SDA orientation (see the Supporting Information, S3). As discussed in the Supporting Information (S3), SDA orientations A and B are consistently lower in energy than $A^{\prime}$ and $B^{\prime}$, suggesting that any reorientation is likely to involve predominantly exchange between $A$ and $B$. This exchange can be modelled by averaging $\delta_{\text {iso }}$ calculated for models containing the SDA in orientations A (Figure 7) and B (see Figure S3.4). As shown in Figure 10 for models with three $\mathrm{F}$ per unit cell (see Figure S3.10 for models with all $\mathrm{F}$ and $\mathrm{OH}$

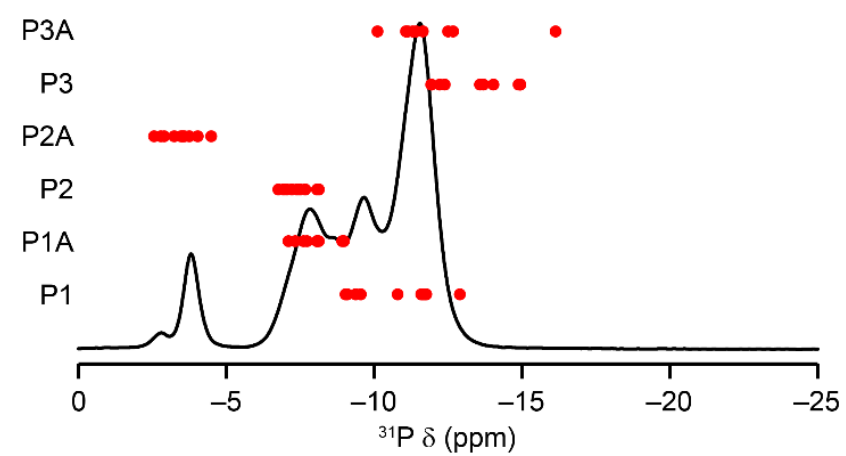

Figure 10. ${ }^{31} \mathrm{P} \delta_{\text {iso }}$ calculated for the different sites in models of GaP0-34A[mimH] with $3 \mathrm{~F}$ anions per unit cell (and all other anion sites occupied by $\mathrm{OH}$ ). Calculated points are overlaid onto the experimental spectrum presented in Figure 3. Each point is calculated as the average shift for that $P$ site with the SDA in orientations $\mathrm{A}$ and $\mathrm{B}$ to model rapid SDA reorientation. Data from favorable (negative $E_{\text {mix }}$ ) and unfavorable (positive $\mathrm{E}_{\mathrm{mix}}$ ) models are not distinguished.

combinations), this averaging provides a much better agreement with the experimental ${ }^{31} \mathrm{P}$ NMR spectrum than calculated parameters assuming only one orientation of the SDA is present (note that points for P3 and P3A with lower calculated $\delta_{\text {iso }}$ in this model tend to have anion site 4 fluorinated, so such shifts are unlikely to be observed experimentally). The reorientation of the SDA molecules is also consistent with the very different ${ }^{19} \mathrm{~F} \quad \mathrm{~T}_{1}$ values observed for F3 compared to F1 and F2, since F1 and F2 are located on the pore walls of GaPO-34A and are, therefore, more exposed to any interactions between the SDA and the framework than F3, which is embedded within the inorganic part of the material (see Figure 1).

\section{Disorder in GaPO-34A[pyH]}

While not discussed in detail here, all NMR spectra recorded for GaPO-34A[pyH] are very similar in appearance to those for GaPO-34A[mimH], suggesting that the same types of disorder are present in both materials and the spectral assignments are similar (see Figure S2.3 for additional spectra). One point of note is that the DFT calculations for GaPO-34A[mimH] suggest that the SDA orientation may affect the relative stabilities of different arrangements of anion occupancies, such that it may not be particularly surprising that using an entirely different organic species leads to a different ratio of F1 : F2 : F3, as reported in Table 1.

\section{Conclusions}

GaPO-34A represents an intriguing case of a material that displays multiple levels and types of disorder, the detail of which cannot be captured by the average X-ray crystallographic picture. This includes partial occupancy of the anion sites, compositional disorder arising from occupancy of the anion sites by the isoelectronic $\mathrm{OH}$ and $\mathrm{F}$ (and concomitant positional disorder in the framework) and multiple orientations of the SDA, which appear to interconvert dynamically at higher temperature. Indeed, given that GaPO-34A is the kinetic product of the synthetic process (with CHA-type GaPO-34 being the thermodynamic product), and given the extensive disorder present in GaPO-34A, it is not surprising that the material 
only forms small crystals that lead to a very challenging structure determination by diffraction methods alone. However, by combining X-ray crystallography (previously reported ${ }^{39}$ ), multinuclear NMR experiments and periodic DFT calculations for a range of structural models, it has been possible to obtain a significant level of local structural detail for this complex material.

Fluorination was found to be most favorable on anion sites 1, 2 and 3, with sites 4 and 5 preferentially occupied by $\mathrm{OH}$. However, at the compositions obtained experimentally, DFT calculations suggested that some fluorination of site 5 may be possible, especially in conjunction with $\mathrm{OH}$ on site 3 to provide favorable $\mathrm{O}-\mathrm{H} \cdots \mathrm{O}_{\text {(framework) }}$ hydrogen bonding. The experimental crystal structure of GaPO-34A[mimH] contains three possible orientations of the mi cations (and two possible arrangements of $\mathrm{N}$ atoms on the ring for each orientation). DFT calculations suggested that the A and B orientations were energetically similar and evidence from variable-temperature ${ }^{13} \mathrm{C},{ }^{19} \mathrm{~F}$ and ${ }^{31} \mathrm{P}$ NMR spectra as well as the absence of signal in a ${ }^{71} \mathrm{Ga}$ STMAS NMR spectrum and the different ${ }^{19} \mathrm{~F} \mathrm{~T}_{1}$ relaxation times for $\mathrm{F} 3$ relative to F1 and F2, suggested that the SDA dynamically reorients on the microsecond timescale. Despite this very complicated structural behavior, it was still possible to assign the ${ }^{19} \mathrm{~F}$ and ${ }^{31} \mathrm{P}$ NMR spectra of both the methylimidazolium and pyridinium forms of GaPO-34A, although further high-field, high-resolution experiments would be required to determine accurate ${ }^{71} \mathrm{Ga}$ NMR parameters for the material.

The methodology described here illustrates the level of structural insight that is now possible for highly complex materials that is hidden in diffraction studies, by combining local spectroscopy with computation and with reference to average crystal structures. This approach is applicable to many classes of materials, particularly hybrid organic-inorganic materials, where conformational disorder or organic components is likely to be commonplace. This will include not only the type of templated materials we have studied here, but other families of materials, such as metal-organic frameworks and coordination polymers.

\section{ASSOCIATED CONTENT}

Supporting Information. Additional NMR experimental details, additional NMR spectra, DFT calculations with different SDA orientations. This material is available free of charge via the Internet at http://pubs.acs.org.

\section{AUTHOR INFORMATION}

\section{Corresponding Authors}

* sema@st-andrews.ac.uk (SEA)

* dmd7@st-andrews.ac.uk (DMD)

Notes

The authors declare no competing financial interest.

\section{ACKNOWLEDGMENT}

SEA, DMD, JEH and DM thank the ERC (EU FP7 Consolidator Grant 614290 "EXONMR") for funding. SEA would like to thank the Royal Society and the Wolfson Foundation for a merit award. The National High Magnetic Field Laboratory is supported by National Science Foundation Cooperative Agreement DMR-1644779 and the State of Florida. Development of the $36 \mathrm{~T}$ SCH magnet and NMR instrumentation was supported by NSF (DMR-1039938 and DMR-0603042) and NIH (BTRR 1P41 GM122698). The UK $850 \mathrm{MHz}$ solid-state NMR Facility used in this research was funded by EPSRC and BBSRC (contract reference PR140003), as well as the University of Warwick including via part funding through Birmingham Science City Advanced Materials Projects 1 and 2 supported by Advantage West Midlands (AWM) and the European Regional Development Fund (ERDF). Collaborative assistance from the $850 \mathrm{MHz}$ Facility Manager (Dr Dinu Iuga, University of Warwick) is acknowledged. The research data supporting this publication can be accessed at DOI: $10.17630 / \mathrm{d} 7 \mathrm{ea} 0 \mathrm{~d} 6 \mathrm{e}-4620-4 \mathrm{c} 5 \mathrm{~d}-$ 8734-38d355e2716f 59

\section{REFERENCES}

(1) Apperley, D. C.; Harris, R. K.; Hodgkinson, P. Solid-State NMR: Basic Principles and Practice. Momentum Press, New York, NY, 2012.

(2) Moran, R. F.; Dawson D. M.; Ashbrook, S. E. Exploiting NMR Spectroscopy for the Study of Disorder in Solids. Int. Rev. Phys. Chem., 2017, 36, 39.

(3) Ashbrook, S. E.; Dawson, D. M. Exploiting Periodic FirstPrinciples Calculations in NMR Spectroscopy of Disordered Solids. Acc. Chem. Res., 2013, 46, 1964.

(4) Ashbrook, S. E.; McKay, D. Combining Solid-State NMR Spectroscopy with First-Principles Calculations - a Guide to NMR Crystallography. Chem. Comm., 2016, 52, 7186.

(5) Sneddon, S.; Dawson, D. M.; Pickard, C. J.; Ashbrook, S. E. Calculating NMR Parameters in Aluminophosphates: Evaluation of Dispersion Correction Schemes. Phys. Chem. Chem. Phys., 2014, 16, 2660.

(6) Chang, B. K.; Bristowe, N. C.; Bristowe, P. D.; Cheetham, A. K. Van der Waals Forces in the Perfluorinated Metal-Organic Framework Zinc 1,2-Bis(4-Pyridyl)Ethane Tetrafluoroterephthalate. Phys. Chem. Chem. Phys., 2012, 14, 7059.

(7) NMR Crystallography. ed. Harris, R. K.; Wasylishen, R. E.; Duer, M. J. John Wiley \& Sons, Chichester, UK, 2009.

(8) Taulelle, F.; Bouchevreau, B.; Martineau, C. NMR Crystallography Driven Structure Determination: Nanoporous Materials. CrystEngComm, 2013, 15, 8613.

(9) Florian, P.; Massiot, D. Beyond Periodicity: Probing Disorder in Crystalline Materials by Solid-State Nuclear Magnetic Resonance Spectroscopy. CrystEngComm, 2013, 15, 8623.

(10) Taulelle, F. NMR Crystallography: Crystallochemical Formula and Space Group Selection. Solid State Sci., 2004, 6, 1053.

(11) Martineau, C.; Cadiau, A.; Bouchevreau, B.; Senker, J.; Taulelle, F.; Adil, K. SMARTER Crystallography of the Fluorinated Inorganic-Organic Compound $\mathrm{Zn}_{3} \mathrm{Al}_{2} \mathrm{~F}_{12} \cdot[\mathrm{HAmTAZ}]_{6}$. Dalton Transact., 2012, 20, 6232 .

(12) Bryce, D. L. NMR Crystallography: Structure and Properties of Materials from Solid-State Nuclear Magnetic Resonance Observables. IUCrJ, 2017, 4, 350.

(13) Baias, M.; Dumez, J.-N.; Svensson, P. H.; Schantz, S.; Day, G. M.; Emsley, L. De Novo Determination of the Crystal Structure of a Large Drug Molecule by Crystal Structure Prediction-Based Powder NMR Crystallography. J. Am. Chem. Soc., 2013, 135, 17501.

(14) Widdifield, C. M.; Nilsson Lill, S. 0; Broo, A.; Lindkvist, M.; Pettersen, A.; Svensk Ankarberg, A.; Aldred, P.; Schantz, S.; Emsley, L. Does Z' Equal 1 or 2? Enhanced Powder NMR Crystallography Verification of a Disordered Room Temperature Crystal Structure of a p38 Inhibitor for Chronic Obstructive Pulmonary Disease. Phys. Chem. Chem. Phys., 2017, 19, 16650. 
(15) Salager, E.; Day, G. M.; Stein, R. S.; Pickard, C. J.; Elena, B.; Emsley, L. Powder Crystallography by Combined Crystal Structure Prediction and High-Resolution ${ }^{1} \mathrm{H}$ Solid-State NMR Spectroscopy. J. Am. Chem. Soc., 2010, 132, 2564.

(16) Hofstetter, A.; Balodis, M.; Paruzzo, F. M.; Widdifield, C. M.; Stevanato, G.; Pinon, A. C.; Bygrave, P. J.; Day, G. M.; Emsley. L. Rapid Structure Determination of Molecular Solids Using Chemical Shifts Directed by Unambiguous Prior Constraints. J. Am. Chem. Soc., 2019, 141, 16624.

(17) Martineau-Corcos, C. NMR Crystallography: A Tool for the Characterization of Microporous Hybrid Solids. Curr. Op. Coll. Interf. Sci., 2018, 33, 35.

(18) Brouwer, D. H. NMR Crystallography of Zeolites: Refinement of an NMR-Solved Crystal Structure Using ab Initio Calculations of ${ }^{29} \mathrm{Si}$ Chemical Shift Tensors. J. Am. Chem. Soc., 2008, 130, 6306.

(19) Brouwer, D. H. Structure Solution of Network Materials by Solid-State NMR without Knowledge of the Crystallographic Space Group. Solid State Nucl. Magn. Reson., 2013, 51, 37.

(20) Brouwer, D. H.; Darton, R. J.; Morris, R. E.; Levitt, M. H. A Solid-State NMR Method for Solution of Zeolite Crystal Structures. J. Am. Chem. Soc., 2005, 127, 10365.

(21) Brouwer, D. H.; Moudrakovski, I. L.; Darton R. J.; Morris, R. E. Comparing Quantum-Chemical Calculation Methods for Structural Investigation of Zeolite Crystal Structures by SolidState NMR Spectroscopy. Magn. Reson. Chem., 2010, 48, S113.

(22) Brouwer, D. H.; Langendoen, K. P. A Graph Theory Approach to Structure Solution of Network Materials from TwoDimensional Solid-State NMR Data. CrystEngComm, 2013, 15, 8748.

(23) Brouwer, D. H.; Van Huizen, J. NMR Crystallography of Zeolites: How Far Can We Go without Diffraction Data? Magn. Reson. Chem., 2019, 57, 167.

(24) Martineau, C.; Mellot-Draznieks, C.; Taulelle, F. NMR Crystallography of $\mathrm{AlPO}_{4}$-CJ2: from the Topological Network to the Local (OH)/F Distribution. Phys. Chem. Chem. Phys., 2011, 13, 18078.

(25) Martineau, C.; Bouchevreau, B.; Tian, Z.; Lohmeier, S.-J.; Behrens, P.; Taulelle, F. Beyond the Limits of X-ray Powder Diffraction: Description of the Nonperiodic Subnetworks in Aluminophosphate-Cloverite by NMR Crystallography. Chem. Mater., 2011, 23, 4799.

(26) Dawson, D. M.; Seymour, V. R.; Ashbrook, S. E. Effects of Extraframework Species on the Structure-Based Prediction of ${ }^{31} \mathrm{P}$ Isotropic Chemical Shifts of Aluminophosphates. J. Phys. Chem. C, 2017, 121, 28065.

(27) Bouchevreau, B.; Martineau, C.; Mellot-Draznieks, C.; Dutour, J.; Tuel, A.; Suchomel, M. R.; Trébosc, J.; Lafon, 0.; Amoureux, J.-P.; Taulelle, F. An NMR-Driven Crystallography Strategy to Overcome the Computability Limit of Powder Structure Determination: A Layered Aluminophosphate Case. Chem. Eur. J., 2013, 19, 5009.

(28) Seymour, V. R.; Eschenroeder, E. C. V.; Castro, M.; Wright, P. A.; Ashbrook, S. E. Application of NMR Crystallography to the Determination of the Mechanism of Charge-Balancing in Organocation-Templated AlPO STA-2. Phys. Chem. Chem. Phys., 2013, 15, 8668.

(29) Florian, P.; Veron, E.; Green, T. F. G.; Yates, J. R.; Massiot, D. Elucidation of the $\mathrm{Al} / \mathrm{Si}$ Ordering in Gehlenite $\mathrm{Ca}_{2} \mathrm{Al}_{2} \mathrm{SiO}_{7}$ by Combined ${ }^{29} \mathrm{Si}$ and ${ }^{27} \mathrm{Al} \mathrm{NMR} \mathrm{Spectroscopy/Quantum} \mathrm{Chemical}$ Calculations. Chem. Mater., 2012, 24, 4068.

(30) Reader, S. W.; Mitchell, M. R.; Johnston, K. E.; Pickard, C. J.; Whittle, K. R.; Ashbrook, S. E. Cation Disorder in Pyrochlore Ceramics: ${ }^{89}$ Y MAS NMR and First-Principles Calculations. J. Phys. Chem. C, 2009, 113, 18874.

(31) Moran, R. F.; McKay, D.; Tornstrom, P. C.; Aziz, A.; Fernandes, Grau-Crespo, R.; Ashbrook, S. E. Ensemble-Based Modeling of the NMR Spectra of Solid Solutions: Cation Disorder in $\mathrm{Y}_{2}(\mathrm{Sn}, \mathrm{Ti})_{2} \mathrm{O}_{7}$. J. Am. Chem. Soc., 2019, 141, 17838.
(32) McKay, D.; Moran, R. F.; Dawson, D. M.; Griffin, J. M.; Sturniolo. S.; Pickard, C. J.; Berry A. J.; Ashbrook, S. E. A Picture of Disorder in Hydrous Wadsleyite-Under the Combined Microscope of Solid-State NMR Spectroscopy and ab Initio Random Structure Searching. J. Am. Chem. Soc., 2019, 141, 3024.

(33) Griffin, J. M.; Yates, J. R.; Berry, A. J.; Wimperis, S.; Ashbrook, S. E. High-Resolution ${ }^{19}$ F MAS NMR Spectroscopy: Structural Disorder and Unusual J Couplings in a Fluorinated Hydroxy-Silicate. J. Am. Chem. Soc., 2010, 132, 15651.

(34) Dawson, D. M.; Griffin, J. M.; Seymour, V. R.; Wheatley, P. S.; Amri, M.; Kurkiewicz, T.; Guillou, N.; Wimperis, S.; Walton, R. I.; Ashbrook, S. E. A Multinuclear NMR Study of Six Forms of AlPO34: Structure and Motional Broadening. J. Phys. Chem. C, 2017, $121,1781$.

(35) Dawson, D. M.; Walton, R. I.; Wimperis, S.; Ashbrook, S. E. The Ambient Hydration of the Aluminophosphate JDF-2 to AlPO53(A): Insights from NMR Crystallography. Acta. Cryst., 2017, C73, 191.

(36) Antonijevic, S.; Ashbrook, S. E.; Biedasek, S.; Walton, R. I.; Wimperis, S.; Yang, H. Dynamics on the Microsecond Timescale in Microporous Aluminophosphate AlPO-14 as Evidenced by ${ }^{27} \mathrm{Al}$ MQMAS and STMAS NMR Spectroscopy. J. Am. Chem. Soc., 2006, 128,8054 .

(37) Ashbrook, S. E.; Cutajar, M.; Griffin, J. M.; Lethbridge, Z. A. D.; Walton, R. I.; Wimperis, S. Transformation of AlPO-53 to JDF-2: Reversible Dehydration of a Templated Aluminophosphate Studied by MAS NMR and Diffraction. J. Phys. Chem. C, 2009, 113, 10780.

(38) Schott-Darie, C.; Kessler, H.; Soulard, M.; Gramlich, V.; Benazzi, E. Diversity of the System $\mathrm{Ga}_{2} \mathrm{O}_{3}-\mathrm{P}_{2} \mathrm{O}_{5}-\mathrm{H}_{2} \mathrm{O}-\mathrm{HF}$ in the Presence of Organic Species. Stud. Surf. Sci. Catal., 1994, 84, 101.

(39) Broom, L. K.; Clarkson, G. J.; Guillou, N.; Hooper, J. E.; Dawson, D. M.; Tang, C. C.; Ashbrook, S. E.; Walton, R. I. A Gel Aging Effect in the Synthesis of Open-Framework Gallium Phosphates: Structure Solution and Solid-State NMR of a LargePore, Open-Framework Material. Dalton Transact., 2017, 46, 16895.

(40) Dawson, D. M. PhD. Thesis, University of St Andrews, 2014.

(41) Gan, Z.; Hung, I.; Wang, X.; Paulino, J.; Wu, G.; Litvak, I. M.; Gor'kov, P. L.; Brey, W. W.; Lendi, P.; Schiano, J. L.; Bird, M. D.; Dixon, I. R.; Toth, J.; Boebinger G. S.; Cross, T. A. NMR Spectroscopy up to 35.2 T using a Series-Connected Hybrid Magnet. J. Magn. Reson., 2017, 284, 125.

(42) Harris, R. K.; Becker, E. D.; Cabral de Menezes, S. M.; Goodfellow, R.; Granger, P. NMR Nomenclature. Nuclear Spin Properties and Conventions for Chemical Shifts (IUPAC Recommendations 2001). Pure. Appl. Chem., 2001, 73, 1795.

(43) Clark, S. J.; Segall, M. D.; Pickard, C. J.; Hasnip, P. J.; Probert, M. J.; Refson, K.; Payne, M. C. First Principles Methods using CASTEP. Z. Krist., 2005, 220, 567.

(44) Pickard, C. J.; Mauri, F. All-Electron Magnetic Response with Pseudopotentials: NMR Chemical Shifts Phys. Rev. B, 2001, 63, 245101.

(45) Perdew, J. P.; Burke K.; Ernzerhof, M. Generalized Gradient Approximation Made Simple. Phys. Rev. Lett., 1996, 77, 3865.

(46) Tkatchenko, A.; Scheffler, M. Accurate Molecular Van Der Waals Interactions from Ground-State Electron Density and FreeAtom Reference Data. Phys. Rev. Lett., 2009, 102, 073005.

(47) McNellis, E. R.; Meyer J.; Reuter, K. Azobenzene at Coinage Metal Surfaces: Role of Dispersive van der Waals Interactions. Phys. Rev. B: Condens. Matter Mater. Phys., 2009, 80, 205414.

(48) Cook, D. S.; Hooper, J. E.; Dawson, D. M.; Ashbrook, S. E.; Fisher, J. M.; Thompsett, D.; Walton, R. I. Synthesis and Polymorphism of Mixed Aluminum-Gallium Oxides. Inorg. Chem., 2020, 59, 3805.

(49) Monkhorst, H. J.; Pack, J. D. Special Points for BrillouinZone Integrations. Phys. Rev. B, 1976, 13, 5188.

(50) Pyykko, P. Year-2017 Nuclear Quadrupole Moments. Mol. Phys., 2018, 116, 1328. 
(51) Weigel, S. J.; Morris, R. E.; Stucky, G. D.; Cheetham, A. K. Synthesis and Crystal Structure of a Gallium Phosphate with 14Ring Channels. J. Mater. Chem., 1998, 8, 1607.

(52) Amri, M.; Ashbrook, S. E.; Dawson, D. M.; Griffin, J. M.; Walton, R. I.; Wimperis, S. A Multinuclear Solid-State NMR Study of Templated and Calcined Chabazite-Type GaPO-34. J. Phys. Chem. C, 2012, 116, 15048.

(53) Delevoye, L.; Fernandez, C.; Morais, C. M.; Amoureux, J.-P.; Rocha, J. Double-Resonance Decoupling for Resolution Enhancement of ${ }^{31} \mathrm{P}$ Solid-State MAS and ${ }^{27} \mathrm{Al} \rightarrow{ }^{31} \mathrm{P}$ MQHETCOR NMR. Solid State Nucl. Magn. Reson., 2002, 22, 501.

(54) Delevoye, L.; Trébosc, J.; Gan, Z.; Montagne, L.; Amoureux, J.-P. Resolution Enhancement using a new Multiple-Pulse Decoupling Sequence for Quadrupolar Nuclei. J. Magn. Reso., 2007, 186, 94.

(55) Kouvatas, C.; Kanwal, N.; Trebosc, J.; Roiland, C.; Delevoy, L.; Ashbrook, S. E.; Le Fur, E.; Le Pollès, L. Rationalization of SolidState NMR Multi-Pulse Decoupling Strategies: Coupling of Spin $\mathrm{I}=1 / 2$ and Half-Integer Quadrupolar Nuclei. J. Magn. Reson., 2019, 303,48 .

(56) NMR of Quadrupolar Nuclei in Solid Materials. Eds Wasylishen, R. E.; Ashbrook, S. E.; Wimperis, S. John Wiley \& Sons, Chichester, UK, 2012.

(57) Colaux, H.; Dawson, D. M.; Ashbrook, S. E. Efficient Amplitude-Modulated Pulses for Triple- to Single-Quantum Coherence Conversion in MQMAS NMR. J. Phys. Chem. A., 2014, $118,6018$.

(58) Thrippleton, M. J.; Cutajar, M.; Wimperis, S. Magic Angle Spinning (MAS) NMR Linewidths in the Presence of Solid-State Dynamics. Chem. Phys. Lett., 2008, 452, 233.

(59) Ashbrook, S. E.; Dawson, D. M.; Gan, Z.; Hooper, J. E.; Hung, I.; Macfarlane, L. E.; McKay, D.; McLeod, L. K.; Walton, R. I. Extensive Local Structural Disorder in the Gallophosphate GaPO34A Revealed by NMR Crystallography. Dataset. University of St Andrews Research Portal. DOI: 10.17630/d7ea0d6e-4620-4c5d8734-38d355e2716f. 
For Table of Contents Only

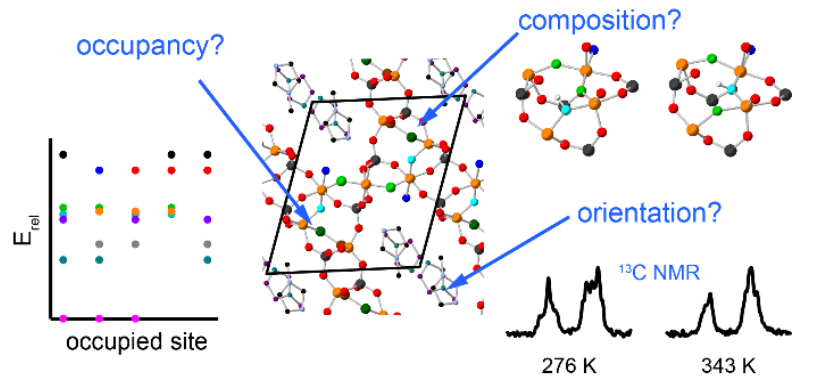

Using an in-depth NMR crystallographic approach, we demonstrate how even extensive structural disorder in complex materials, hidden in conventional crystallography, can be described from a local atomic perspective. In the gallophosphate GaPO-34, we combine multinuclear NMR experiments and periodic DFT calculations with existing X-ray crystallography to reveal the disorder of vacancies, fluoride and hydroxide across the anion sublattice, as well as microsecondtimescale dynamics of the guest molecules. 